\title{
BMJ Open Association of high-sensitivity C-reactive protein in middle-aged and elderly Chinese people with hyperuricaemia and risk of coronary heart disease: a cross-sectional study
}

\author{
Mingsheng Xie, ${ }^{1}$ Dongxing Xie, ${ }^{1}$ Ye Yang, ${ }^{1}$ Yi Zhang, ${ }^{1}$ Kun Li, ${ }^{1}$ Bin Zhou, ${ }^{1}$ \\ Zidan Yang, ${ }^{2}$ Xiang Ding, ${ }^{1}$ Hui Li (D) ${ }^{1,3,4}$
}

To cite: Xie M, Xie D,

Yang Y, et al. Association of high-sensitivity C-reactive protein in middle-aged and elderly Chinese people with hyperuricaemia and risk of coronary heart disease: a crosssectional study. BMJ Open 2019;9:e028351. doi:10.1136/ bmjopen-2018-028351

\section{- Prepublication history for} this paper is available online. To view these files, please visit the journal online (http://dx.doi. org/10.1136/bmjopen-2018028351).

$\mathrm{MX}$ and $\mathrm{DX}$ contributed equally. $\mathrm{XD}$ and $\mathrm{HL}$ contributed equally.

Received 04 December 2018 Revised 14 September 2019 Accepted 17 September 2019

Check for updates

(c) Author(s) (or their employer(s)) 2019. Re-use permitted under CC BY-NC. No commercial re-use. See rights and permissions. Published by BMJ.

For numbered affiliations see end of article.

Correspondence to

Dr Hui Li; lihui1988@csu.edu.cn

Dr Xiang Ding;

dingxiang@csu.edu.cn

\section{ABSTRACT}

Objectives Patients with hyperuricaemia are at relatively high risk of developing coronary heart disease (CHD). The purpose of this study was to examine the relationship between high-sensitivity C-reactive protein (hs-CRP) and $\mathrm{CHD}$ risk in a middle-aged and elderly population with hyperuricaemia.

Design A cross-sectional study.

Setting and participants This study was conducted in a health examination centre of China. Participants were diagnosed with hyperuricaemia based on uric acid concentrations. Specifically, males with a uric acid concentration $\geq 416 \mu \mathrm{mol} / \mathrm{L}$ were included, as well as females with a concentration $\geq 360 \mu \mathrm{mol} / \mathrm{L}$.

Main outcome measures 10 -year CHD risk for each individual was evaluated using Framingham risk score based on the Adult Treatment Panel III charts.

Results A total of 517 patients with hyperuricaemia (438 males and 79 females) aged from 40 to 85 years old were included in the present study. $193(37.3 \%)$ patients were defined with relatively high 10 -year CHD risk. Compared with the lowest quintile, the crude ORs of relatively high 10-year CHD risks were 1.43 (95\% $\mathrm{Cl} 0.78$ to 2.63 , $\mathrm{p}=0.245), 2.05$ (95\% Cl 1.14 to 3.67, $\mathrm{p}=0.016), 2.77$ (95\% Cl 1.54 to 4.98, $p=0.001$ ), 2.12 (95\% Cl 1.18 to 3.80 , $\mathrm{p}=0.012$ ) in the second, third, fourth and fifth quintiles of serum hs-CRP level, respectively ( $p$ for trend=0.057). The multivariable-adjusted ORs of relatively high 10-year CHD risk were 1.40 (95\% $\mathrm{Cl} 0.75$ to $2.61, \mathrm{p}=0.291)$ in the second, 2.05 (95\% Cl 1.13 to $3.72, p=0.019)$ in the third, $2.69(95 \% \mathrm{Cl} 1.47$ to $4.89, \mathrm{p}=0.001)$ in the fourth and $2.10(95 \% \mathrm{Cl} 1.15$ to $3.84, p=0.016)$ in the fifth quintile of serum hs-CRP level when compared with the lowest quintile ( $p$ for trend $=0.068$ ).

Conclusion This study showed that $\mathrm{ORs}$ of relatively high 10-year CHD risk were raised in patients with hyperuricaemia with higher serum hs-CRP level; however, there was a not significant but borderline trend association and that more research is needed.

\section{BACKGROUND}

Serum uric acid is the catabolic end-product of purine metabolism via the catalysis of

\section{Strengths and limitations of this study}

- This is the first study exploring the association between high-sensitivity C-reactive protein (hs-CRP) and the coronary heart disease (CHD) risk in patients with hyperuricaemia in a middle-aged and elderly population with hyperuricaemia.

- The relationship of hs-CRP and the CHD risk was analysed by multivariable models.

- As result of the nature of cross-sectional design, the causal relationship cannot be established in the present study.

- Though Framingham risk score (FRS) has been used to assess the risk of cardiovascular events in Chinese population, it is noteworthy that FRS was originally constructed for the US population using a US population data.

xanthine oxidase. With the rapid economic development, the dietary habits of Chinese people have changed greatly towards an increasingly heavier intake of meat, dairy products and other purine enriched foods, which has led to a higher prevalence of hyperuricaemia and gout susceptibly. ${ }^{12} \mathrm{~A}$ systematic review and meta-analysis involving 44 studies showed that the pooled prevalence of hyperuricaemia was $13.3 \%$ in mainland China from 2000 to $2014 .^{3}$ Some previous studies reported that an increase in serum uric acid was incriminated in the pathogenesis of metabolic syndrome, ${ }^{45}$ chronic kidney disease,${ }^{67}$ stroke $^{8}$ and coronary heart disease (CHD).$^{9} 10$

Over the past several decades, relevant studies have shown that an increased serum uric acid was significantly associated with CHD, independent of conventional CHD risk factors. ${ }^{9-12}$ Besides, it was also demonstrated that increased uric acid was correlated with 
hypertension, diabetes mellitus, metabolic syndrome, hypertriglyceridemia and endothelial dysfunction. ${ }^{6}{ }^{13-19}$ All of this could lead to an increased risk of CHD. With the trend of population ageing, CHD has become one of the most common causes of death. ${ }^{20}$ Therefore, it is urgent to seek effective predictors or biomarkers to identify subjects at a high risk of CHD, especially among the patients with hyperuricaemia, who are deemed a high risk group of CHD. A wide array of studies indicated that inflammation was involved in the pathogenesis of CHD. ${ }^{21}{ }^{22} \mathrm{C}$-reactive protein (CRP), one of the acute phase respondents, is commonly used in clinical practice to reflect chronic inflammation as an inexpensive measurement. ${ }^{23}$ Several epidemiological studies were undertaken to clarify the relationship between CRP and CHD, but no agreement has been reached. ${ }^{24-26}$ To the best of the authors' knowledge, there has been no study yet examining the association between high-sensitivity (hs)-CRP and the CHD risk in patients with hyperuricaemia. Meaningful outcomes in this respect would have important implications in understanding the pathophysiological mechanisms of CHD in patients with hyperuricaemia and contribute to the development of a simple and inexpensive method to predict the future CHD risk of this population.

To fill this knowledge gap, the present cross-sectional study was carried out to clarify the correlation between hs-CRP and the 10-year estimated CHD risk measured by the Framingham risk score (FRS) in the middle-aged and elderly population with hyperuricaemia, with adjustment of conventional cardiovascular risk factors.

\section{MATERIALS AND METHODS \\ Study population}

The participants of the present cross-sectional study were chosen from a pool of subjects who were undergoing routine medical examinations at the Department of Health Examination Center Xiangya Hospital, Central South University in Changsha, Hunan Province of China. The detailed methodology has been described in some earlier studies. ${ }^{27-32}$ Briefly, all the qualified participants must be 40 years old or above and undergoing measurements of serum uric acid, hs-CRP, fasting plasma glucose concentration, total cholesterol, high-density lipoprotein (HDL-cholesterol) and creatinine during the specified period. In addition, the subjects should be diagnosed with hyperuricaemia (ie, the uric acid $\geq 416 \mu \mathrm{mol} / \mathrm{L}$ for male and $\geq 360 \mu \mathrm{mol} / \mathrm{L}$ for female), with availability of demographic and clinical data including age, gender, body mass index (BMI) (weight/height ${ }^{2}$ ), smoking status, alcohol drinking status, activity level, medication status and so on. Initially, a total of 5994 subjects were included based on the age requirement and availability of blood biochemical assessments (serum uric acid and hs-CRP measurement) during the period of October 2013 to December 2015. Then, 3420 subjects were disqualified: 30 were lack of basic health characteristics such as blood pressure and BMI and 3390 were lack of information of health-related habits. Of the remaining 2574 subjects, only 517 were diagnosed with hyperuricaemia and were finally enrolled in the present study. The study protocol had been reviewed and approved by the local Ethics and Research Committee and the written informed consent had been obtained from all participants prior to execution.

\section{Blood biochemistry}

All blood samples were drawn from the antecubital vein using vacuum tubes after an overnight fast of $\geq 12$ hours, and were kept at $4^{\circ} \mathrm{C}$ until analysis. The hs-CRP was detected by the Latex turbidity method. The fasting plasma glucose concentration was measured using the glucose oxidase enzyme method. The uric acid, total cholesterol, HDL-cholesterol and creatinine were all detected using a Beckman Coulter AU 5800 (Beckman Coulter, Brea, California, USA). The low concentrations $(2.5 \mathrm{mmol} / \mathrm{L}$ for glucose and $118 \mu \mathrm{mol} / \mathrm{L}$ for uric acid $)$ and high concentrations $(6.7 \mathrm{mmol} / \mathrm{L}$ for glucose and 472 $\mu \mathrm{mol} / \mathrm{L}$ for uric acid) of standard human samples were used, respectively, to evaluate the intra-assay and interassay coefficients of variation. The intra-assay coefficients of variation were $0.98 \%(2.5 \mathrm{mmol} / \mathrm{L})$ and $1.72 \%(6.7$ $\mathrm{mmol} / \mathrm{L})$ for glucose, $1.39 \%(118 \mu \mathrm{mol} / \mathrm{L})$ and $0.41 \%$ $(472 \mu \mathrm{mol} / \mathrm{L})$ for uric acid. The interassay coefficients of variation were $2.45 \%(2.5 \mathrm{mmol} / \mathrm{L})$ and $1.46 \%(6.7$ $\mathrm{mmol} / \mathrm{L})$ for glucose, $1.40 \%(118 \mu \mathrm{mol} / \mathrm{L})$ and $1.23 \%$ $(472 \mu \mathrm{mol} / \mathrm{L})$ for uric acid. A subject was diagnosed with diabetes mellitus if his/her fasting plasma glucose level $\geq 7.0 \mathrm{mmol} / \mathrm{L}$ or if he/she was currently receiving medication for blood glucose control.

\section{Assessment of other exposures}

The BMI was calculated as the weight $(\mathrm{kg})$ divided by the square of the height $(\mathrm{m})$. The blood pressure was detected at the upper arm using an electronic sphygmomanometer after a rest of at least $10 \mathrm{~min}$. Then, the status of physical activity, including the average frequency (never, one to two times per week, three to four times per week, five times and above per week) and the average duration of physical activity (within half an hour, half an hour to 1 hour, 1 to 2 hours, more than 2 hours) was collected from each subject. Last, the smoking and alcohol drinking status as well as the medication conditions of the subjects were inquired.

\section{Assessment of 10-year CHD risk}

The risk level of developing CHD was measured by the FRS according to The Adult Treatment Panel III (ATP III) charts, ${ }^{33}$ and the FRS was calculated based on seven risk factors, which are age, gender, smoking, systolic blood pressure, use of antihypertensive medication, total cholesterol and HDL cholesterol, respectively. The specific risk scoring process is as follows: (1) calculate the number of points for each risk factor; (2) sum up the points of each risk factor to obtain the total risk score; (3) generate the estimated 10-year CHD risk for each patient. The subjects 
with the 10 -year risk above $10 \%$ were classified into the high 10-year CHD risk group.

\section{Statistical analysis}

For statistical analysis, the continuous variables with a normal distribution were presented as mean $\pm \mathrm{SD}$, and the category variables were described by frequency and percentage. The participants were classified into five categories based on the quintile distribution of hs-CRP, namely $\leq 0.50,0.51-0.90,0.91-1.63,1.63-3.04$ and $\geq 3.05 \mathrm{mg} / \mathrm{L}$. Baseline characteristics were presented according to quintiles of hs-CRP, and their trend associations were assessed using a linear regression analysis for continuous variables or a logistic regression for category variables, with the median value of hs-CRP in each category assigned to the corresponding category. The association between hs-CRP and the CHD risk has been described as the OR and 95\% CIs, which were calculated for each quintile of hs-CRP; the lowest quintile was regarded as the reference category. Then, the factors of BMI, educational background, alcohol drinking status, activity level, serum creatinine and diabetes that might affect both hs-CRP and the outcomes of interest were included in these models as adjustors. The trend for relatively high CHD risk according to quartile of hs-CRP was analysed using the linear regression model. All data analyses were performed using SPSS 18.0 (SPSS, Chicago, Illinois, USA), and the level for statistical significance was set as the $p$ value equal to 0.05 . All tests were two tailed.

\section{Patient and public involvement}

Patients and the public were not involved in setting the research question or the outcome measures, nor were they involved in the design or implementation of the study. There were no plans to disseminate the results of the research to study participants.

\section{RESULTS}

A total of 517 patients with hyperuricaemia (438 males and 79 females) aged from 40 to 85 years old were included in the present study. There were 193 (37.3\%) patients were defined with relatively high 10-year CHD risk. The basic characteristics of study population based on the quintiles of hs-CRP are shown in table 1. Patients with hyperuricaemia in the highest level group of hs-CRP were more likely to have a higher BMI and lower activity level than were those in the lowest level group ( $p$ for trend $<0.05$ for all).

The results of the associations between hs-CRP and relatively high 10 -year CHD risk $(\geq 10 \%)$ are shown in table 2. According to the crude OR values, a higher prevalence of relatively high CHD risk was observed in the highest quintile ( $\mathrm{OR}=2.12,95 \%$ CI 1.18 to $3.80, \mathrm{p}=0.012$ ) of hs-CRP when comparing with the lowest quintile, and $p$ for trend was 0.057. After adjustment for BMI, educational background, alcohol drinking status, activity level, serum creatinine and diabetes, the results did not change materially. Though ORs of relatively high CHD risk were raised in subjects with higher serum hs-CRP level, only a not significant but borderline trend association was observed; the multivariable OR based on a comparison of the highest and the lowest quintile of hs-CRP was 2.10 (95\% CI, 1.15 to 3.84; $\mathrm{p}=0.016$ ), and $\mathrm{p}$ for trend was 0.068 .

\section{DISCUSSION}

The present cross-sectional study revealed a borderline positive association between hs-CRP and the high 10-year risk of CHD in the middle-aged and elderly population with hyperuricaemia. This correlation did not changed significantly with adjustment of several potential confounding factors such as BMI, educational background, alcohol drinking status, activity level, serum creatinine and diabetes. These findings suggested that hs-CRP could serve as a marker for the risk of CHD in patients with hyperuricaemia.

The relationship between CRP and CHD has aroused intensive arguments. Some earlier studies demonstrated that a high level of CRP concentration was positively associated with $\mathrm{CHD}$ and that $\mathrm{CRP}$ was predictive of $\mathrm{CHD}{ }^{34-37}$ For example, in two nested case-control studies-the Nurses' Health Study and the Health Professionals Follow-up Study-Jennifer et al found that a high level of CRP was associated with an increased risk of CHD among participants with no history of cardiovascular disease and that the level of CRP could be considered as a predictor of CHD. ${ }^{38}$ In the Cardiovascular Health Study, elevated CRP was found to be associated with an increased 10-year risk of $\mathrm{CHD}$, regardless of the presence of conventional risk factors. ${ }^{39}$ Besides, a cross-sectional study conducted in Japan demonstrated that hs-CRP was associated with the estimated risk level of CHD in the middle-aged men. ${ }^{25}$ However, controversy remains with respect to the association of CRP with CHD, and the predictive value of CRP. According to the data obtained from the MONICA Optional Haemostasis Study, no significant correlation was observed between the CHD event rate and the plasma CRP in the European populations. ${ }^{24}$ Similarly, it was shown that the CRP level was not significantly associated with CHD with adjustment of conventional risk factors in the postmenopausal women. ${ }^{40}$ Meanwhile, the findings from the 1999-2004 NHANES suggested that hs-CRP was not associated with the CHD mortality. ${ }^{41}$ The present study further revealed that CRP was borderline positively associated with CHD in patients with hyperuricaemia.

It is interesting that, in the present study, the OR for CHD risk was lower in the highest quintile than the fourth quintile of hs-CRP. This phenomenon was also observed in several previous studies. Folsom et al showed that the multivariate-adjusted relative risk of CHD in the fifth quintile of CRP was lower than in the fourth quintile. ${ }^{42}$ Similar result was observed in another study which demonstrated that multivariate-adjusted relative risk of cardiovascular events was lower in the fourth quartile than in the third quartile of CRP. ${ }^{43}$ However, our study 


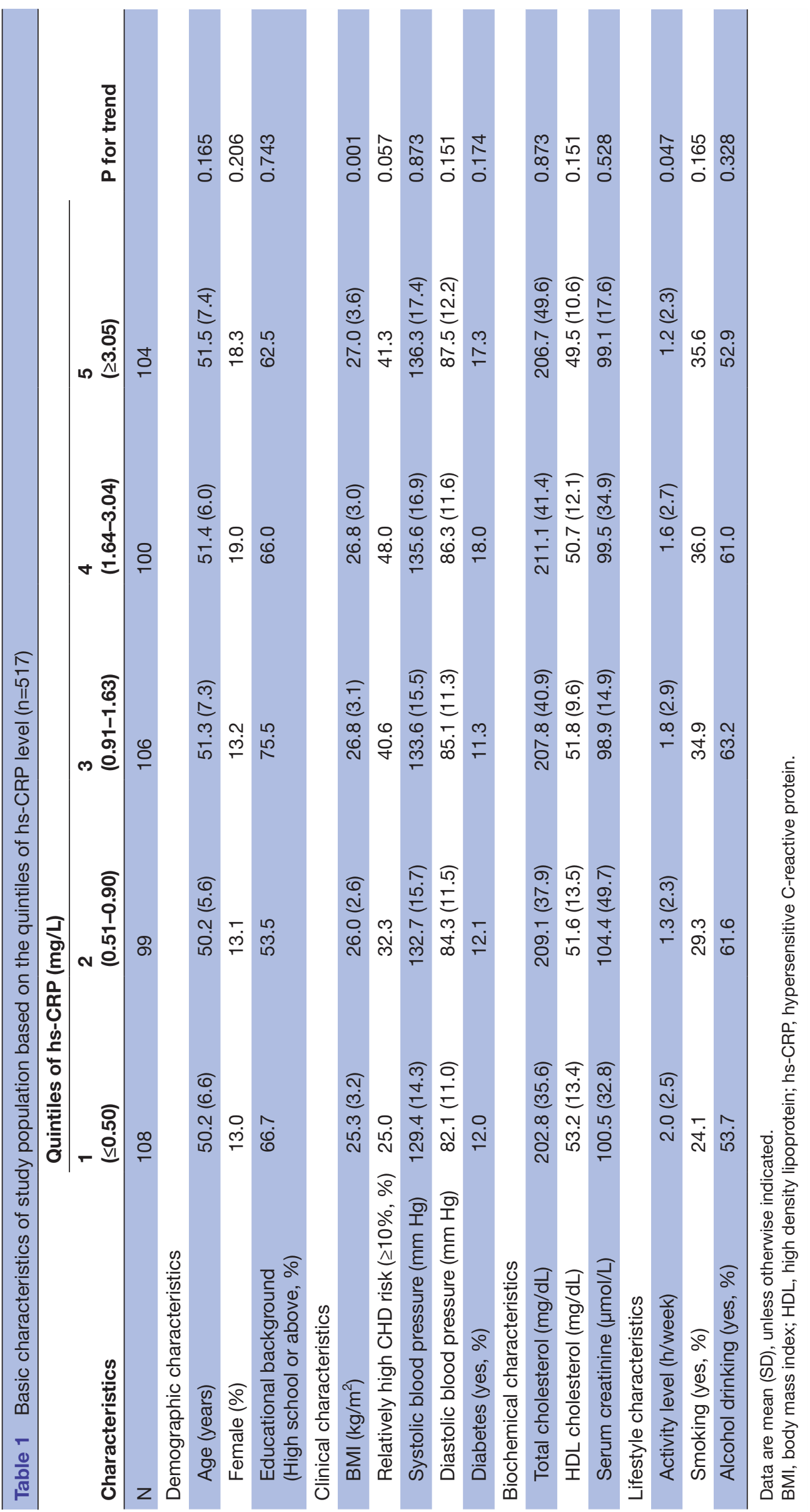


Table 2 Associations between hs-CRP and relatively high 10-year CHD risk $(\geq 10 \%)$ in hyperuricaemia population $(n=517)$

Quintiles of hs-CRP ( $\mathrm{mg} / \mathrm{L})$

\begin{tabular}{|c|c|c|c|c|c|c|}
\hline & $1(\leq 0.50)$ & $2(0.51-0.90)$ & $3(0.91-1.63)$ & $4(1.64-3.04)$ & $5(\geq 3.05)$ & $P$ for trend \\
\hline Participants (n) & 108 & 99 & 106 & 100 & 104 & \\
\hline Median hs-CRP (mg/L) & 0.34 & 0.69 & 1.21 & 2.11 & 6.12 & \\
\hline Crude OR $(95 \% \mathrm{Cl})$ & 1.00 (reference) & $\begin{array}{l}1.43 \\
\text { (0.78 to } 2.63)\end{array}$ & $\begin{array}{l}2.05 \\
(1.14 \text { to } 3.67)\end{array}$ & $\begin{array}{l}2.77 \\
\text { (1.54 to } 4.98)\end{array}$ & $\begin{array}{l}2.12 \\
(1.18 \text { to } 3.80)\end{array}$ & 0.057 \\
\hline$P$ values & - & 0.245 & 0.016 & 0.001 & 0.012 & \\
\hline $\begin{array}{l}\text { Multivariable adjusted OR } \\
(95 \% \mathrm{Cl})^{\star}\end{array}$ & 1.00 (reference) & $\begin{array}{l}1.40 \\
(0.75 \text { to } 2.61)\end{array}$ & $\begin{array}{l}2.05 \\
(1.13 \text { to } 3.72)\end{array}$ & $\begin{array}{l}2.69 \\
(1.47 \text { to } 4.89)\end{array}$ & $\begin{array}{l}2.10 \\
(1.15 \text { to } 3.84)\end{array}$ & 0.068 \\
\hline$P$ values & - & 0.291 & 0.019 & 0.001 & 0.016 & \\
\hline
\end{tabular}

*Multivariable adjusted model was adjusted for BMI, educational background, alcohol drinking status, activity level, serum creatinine and diabetes.

BMI, body mass index; CHD, coronary heart disease; hs-CRP, hypersensitive C-reactive protein.

and these previous studies are all epidemiological studies which cannot establish mechanisms, and additional basic research on this interesting phenomenon is needed.

Previous in vivo and in vitro studies have suggested that CRP modulated many factors involved in atherosclerosis, which might explain the positive association between the CRP level and CHD. CRP could reduce the endothelial nitric oxide synthase both at the protein and mRNA levels and promote the production of inducible nitric oxide synthase and endothelin-1 in endothelial cells. ${ }^{3839}$ Besides, it was reported that the adhesion and internalisation of white blood cells onto the arterial wall were improved by CRP by inducing the expression of vascular cell adhesion molecule-1, intercellular adhesion molecule-1, E-selectin and monocyte chemoattractant protein- $1 .{ }^{44}$ Moreover, CRP could also induce the monocyte chemotaxis and differentiation ${ }^{46}{ }^{47}$ and facilitate the uptake of oxidised low-density lipoprotein through macrophages and monocyte-platelets aggregation. ${ }^{4849}$ Further evidence supported CRP as a participant in later stages of atherosclerosis with the expression of matrix metalloproteinases and collagenase activity in human monocyte-macrophages. ${ }^{50} 51$

The present study clarified that high hs-CRP was correlated with a high CHD risk in the middle-aged and elderly population with hyperuricaemia, while several previous study have shown that CRP was not significantly associated with CHD in general population or other population. ${ }^{24}{ }^{40}$ It is suggested that hyperuricaemia interacts synergistically with high hs-CRP subjects and may subsequently enhance the risk of CHD predictor value of hs-CRP. This has implications for clinicians to predict the CHD risk in patients with hyperuricaemia based on hs-CRP, an easily measured clinical marker, and thereby providing preventive measures accordingly. Meanwhile, it also prompts that uric acid may interact with other risk factors during the development and progression of CHD, but such conclusion needs to be validated by further study.

Several strengths and shortcomings of this study are worth being mentioned. First, this is the first study exploring the association between hs-CRP and the CHD risk in patients with hyperuricaemia in the middle-aged and elderly population. Second, multivariable models were used to analyse the aforementioned relationship by adjusting a considerable number of potential confounding factors, such as BMI, serum creatinine and diabetes. As for the limitations, first, no causal relationship can be established in the present study due to the nature of cross-sectional design. However, the primary objective of this study was to examine the association between CRP and the CHD risk rather than to prove that CRP could increase the incidence of CHD. As CRP was deemed to be correlated with the CHD risk score, it can be used to reflect this complicated index in clinical practice. Subsequently, other more complicated indexes such as the FRS could be used to examine the CHD risk. Therefore, it can be speculated that CRP may have the potential to be an easily accessible screening method in the future after further studies' confirmation. Second, though FRS has been used to assess the risk of cardiovascular events in Chinese population, ${ }^{52}{ }^{53}$ it is noteworthy that FRS was originally constructed for the US population using a US population data. Third, age, sex, blood pressure, cholesterol and smoking should be included in adjusting covariates in multivariate analyses regarding CHD risk. However, FRS was calculated based on seven risk factors: age, gender, smoking, systolic blood pressure, use of antihypertensive medication, total cholesterol and HDL cholesterol. Therefore, we excluded these impotent confounders from adjusting risk factors as previous studies did. ${ }^{545}$

\section{CONCLUSION}

This study showed that ORs of relatively high 10-year CHD risk were raised in patients with hyperuricaemia with higher serum hs-CRP level; however, there was a not significant but borderline trend association and that more research is needed. 


\section{Author affiliations}

${ }^{1}$ Department of Orthopaedics, Xiangya Hospital, Central South University, Changsha China

${ }^{2}$ Department of Epidemiology and Health Statistics, Xiangya School of Public Health, Central South University, Changsha, China

${ }^{3}$ Hunan Key Laboratory of Joint Degeneration and Injury, Changsha, China ${ }^{4}$ National Clinical Research Center of Geriatric Disorders, Xiangya Hospital, Central South University, Changsha, China

Contributors MX, DX, HL and XD were responsible for the conception and design of the study. $K L, B Z$ and $Z Y$ contributed to the statistical analyses. MX, DX, $H L, X D$, $Y Y$ and $Y Z$ contributed to the data collection and interpretation. MX, DX, HL and XD drafted the manuscript. $H L, X D$ and $Z Y$ contributed to the revision of the manuscript. All authors read and approved the final manuscript.

Funding This work was supported by the National Natural Science Foundation of China $(81772413,81702207,81702206)$, the Young Investigator Grant of Xiangya Hospital, Central South University (2017Q10) and the Postgraduate Independent Exploration and Innovation Project of Central South University (2018zzts256).

Competing interests None declared.

Patient consent for publication Not required.

Ethics approval This study was approved by the ethics committee of Xiangya Hospital, Central South University.

Provenance and peer review Not commissioned; externally peer reviewed.

Data availability statement № data are available.

Open access This is an open access article distributed in accordance with the Creative Commons Attribution Non Commercial (CC BY-NC 4.0) license, which permits others to distribute, remix, adapt, build upon this work non-commercially, and license their derivative works on different terms, provided the original work is properly cited, appropriate credit is given, any changes made indicated, and the use is non-commercial. See: http://creativecommons.org/licenses/by-nc/4.0/.

\section{ORCID iD}

Hui Li http://orcid.org/0000-0003-4856-1539

\section{REFERENCES}

1. Hak AE, Choi HK. Lifestyle and gout. Curr Opin Rheumatol 2008;20:179-86.

2. Zhai F-ying, He Y-na, Ma G-sheng, et al. [Study on the current status and trend of food consumption among Chinese population]. Zhonghua Liu Xing Bing Xue Za Zhi 2005;26:485.

3. Liu R, Han C, Wu D, et al. Prevalence of hyperuricemia and gout in mainland China from 2000 to 2014: a systematic review and metaanalysis. Biomed Res Int 2015;2015:1-12.

4. Onat $A$, Uyarel $H$, Hergenç $G$, et al. Serum uric acid is a determinant of metabolic syndrome in a population-based study. Am J Hypertens 2006;19:1055-62.

5. Oda E. Serum uric acid is an independent predictor of metabolic syndrome in a Japanese health screening population. Heart Vessels 2014;29:496-503.

6. Iseki K, Ikemiya Y, Inoue T, et al. Significance of hyperuricemia as a risk factor for developing ESRD in a screened cohort. American Journal of Kidney Diseases 2004;44:642-50.

7. Chang $\mathrm{H}-\mathrm{Y}$, Lee $\mathrm{P}-\mathrm{H}$, Lei C-C, et al. Hyperuricemia as an independent risk factor of chronic kidney disease in middle-aged and elderly population. Am J Med Sci 2010;339:509-15.

8. Li M, Hou W, Zhang X, et al. Hyperuricemia and risk of stroke: a systematic review and meta-analysis of prospective studies. Atherosclerosis 2014;232:265-70.

9. Lai X, Yang L, Légaré S, et al. Dose-Response relationship between serum uric acid levels and risk of incident coronary heart disease in the Dongfeng-Tongji cohort. Int J Cardiol 2016;224:299-304.

10. Braga F, Pasqualetti S, Ferraro $S$, et al. Hyperuricemia as risk factor for coronary heart disease incidence and mortality in the general population: a systematic review and meta-analysis. Clin Chem Lab Med 2016;54:7-15.

11. Kim SY, Guevara JP, Kim KM, et al. Hyperuricemia and coronary heart disease: a systematic review and meta-analysis. Arthrit Care Res 2010:62:170-80.

12. Coutinho T, Turner S, Peyser P, et al. Associations of serum uric acid with markers of inflammation, metabolic syndrome, and subclinical coronary atherosclerosis. Am J Hypertens 2007;20:83-9.
13. Perlstein TS, Gumieniak $O$, Williams $G H$, et al. Uric acid and the development of hypertension: the normative aging study. Hypertension 2006;48:1031-6.

14. Li Q, Yang Z, Lu B, et al. Serum uric acid level and its association with metabolic syndrome and carotid atherosclerosis in patients with type 2 diabetes. Cardiovasc Diabetol 2011;10:72-7.

15. Masuo K, Kawaguchi H, Mikami H, et al. Serum uric acid and plasma norepinephrine concentrations predict subsequent weight gain and blood pressure elevation. Hypertension 2003;42:474-80.

16. Nakanishi $N$, Okamoto $M$, Yoshida $H$, et al. Serum uric acid and risk for development of hypertension and impaired fasting glucose or type II diabetes in Japanese male office workers. Eur J Epidemiol 2003;18:523-30.

17. Dehghan A, van Hoek M, Sijbrands EJG, et al. High serum uric acid as a novel risk factor for type 2 diabetes. Diabetes Care 2008;31:361-2

18. Rathmann W, Funkhouser E, Dyer AR, et al. Relations of hyperuricemia with the various components of the insulin resistance syndrome in young black and white adults: the cardia study. coronary artery risk development in young adults. Ann Epidemiol 1998;8:250-61.

19. Khosla UM, Zharikov S, Finch JL, et al. Hyperuricemia induces endothelial dysfunction. Kidney Int 2005;67:1739-42.

20. Disease L-JH. And stroke Statistics-2009 update: a report from the American heart association statistics Committee and stroke statistics Subcommittee (Vol 119, PG e21, 2009). Circulation 2011;124:E424.

21. Libby $P$, Sukhova G, Lee RT, et al. Cytokines regulate vascular functions related to stability of the atherosclerotic plaque. $J$ Cardiovasc Pharmacol 1995;25 Suppl 2:S9-12.

22. Ross R. Atherosclerosis--an inflammatory disease. N Engl J Med 1999;340:115-26.

23. Savve VD, Ushakov GS, et al. C-reactive protein, a sensitive marker for inflammation, predicts future 20 risk of coronary heart disease in initially healthy middle-aged men: Koenig W, Sund M, Frohlich M, et al: Circulation 1999;99:237-242. Zhurnal Mikrobiologii Epidemiologii I Immunobiologii 1962;33:15-20.

24. Yarnell J, McCrum E, Rumley A, et al. Association of European population levels of thrombotic and inflammatory factors with risk of coronary heart disease: the MONICA optional haemostasis study. Eur Heart J 2005;26:332-42.

25. Otsuka T, Kawada T, Katsumata M, et al. High-Sensitivity C-reactive protein is associated with the risk of coronary heart disease as estimated by the Framingham risk score in middle-aged Japanese men. Int J Cardiol 2008;129:245-50.

26. Danesh J, Wheeler JG, Hirschfeld GM, et al. C-Reactive protein and other circulating markers of inflammation in the prediction of coronary heart disease. ACC Current Journal Review 2004;13:27-8.

27. Zeng $\mathrm{C}$, Li H, Wei J, et al. Association between dietary magnesium intake and radiographic knee osteoarthritis. PLoS One 2015;10:e127666.

28. Zeng C, Wei J, Li H, et al. Relationship between serum magnesium concentration and radiographic knee osteoarthritis. J Rheumatol 2015;42:1231-6.

29. Zeng C, Wang Y-lun, Wei J, et al. Association between low serum magnesium concentration and hyperuricemia. Magnes Res 2015;28:56-63

30. Xie D-xing, Xiong Y-lin, Zeng C, et al. Association between low dietary zinc and hyperuricaemia in middle-aged and older males in China: a cross-sectional study. BMJ Open 2015;5:e8637.

31. Xiong $\mathrm{Y}$, Wei J, Zeng $\mathrm{C}$, et al. Association between dietary iron intake and bone mineral density: a cross-sectional study in Chinese population. Nutr Diet 2016:73:433-40.

32. Li H, Zeng C, Wei J, et al. Associations between dietary antioxidants intake and radiographic knee osteoarthritis. Clin Rheumatol 2016;35:1585-92.

33. National Cholesterol Education Program (NCEP) Expert Panel on Detection, Evaluation, and Treatment of High Blood Cholesterol in Adults (Adult Treatment Panel III). Third report of the National cholesterol education program (NCEP) expert panel on detection, evaluation, and treatment of high blood cholesterol in adults (adult treatment panel III) final report. Circulation 2002;106:3143-421.

34. Cushman M, Arnold AM, Psaty BM, et al. C-Reactive protein and the 10-year incidence of coronary heart disease in older men and women: the cardiovascular health study. Circulation 2005;112:25-31.

35. Straczek C, Ducimetiere P, Barberger-Gateau P, et al. Higher level of systemic $\mathrm{C}$-reactive protein is independently predictive of coronary heart disease in older community-dwelling adults: the Three-City study. J Am Geriatr Soc 2010;58:129-35.

36. Danesh J, Wheeler JG, Hirschfield GM, et al. C-Reactive protein and other circulating markers of inflammation in the prediction of coronary heart disease. N Engl J Med 2004;350:1387-97. 
37. Kaptoge S, Di Angelantonio E, Lowe G, et al. C-Reactive protein concentration and risk of coronary heart disease, stroke, and mortality: an individual participant meta-analysis. Lancet 2010;375:132-40.

38. Venugopal SK, Devaraj S, Yuhanna I, et al. Demonstration that C-reactive protein decreases eNOS expression and bioactivity in human aortic endothelial cells. Circulation 2002;106:1439-41.

39. Verma S, SH L, Badiwala MV, et al. Endothelin antagonism and interleukin-6 inhibition attenuate the proatherogenic effects of C-reactive protein. Circulation 1890;2002:105.

40. Kim HC, Greenland P, Rossouw JE, et al. Multimarker prediction of coronary heart disease risk: the women's health Initiative. J Am Coll Cardiol 2010;55:2080-91.

41. Veeranna V, Zalawadiya SK, Panaich S, et al. Comparative analysis of red cell distribution width and high sensitivity C-reactive protein for coronary heart disease mortality prediction in multi-ethnic population: findings from the 1999-2004 NHANES. Int J Cardiol 2013;168:5156-61.

42. Folsom AR, Aleksic N, Catellier D, et al. C-Reactive protein and incident coronary heart disease in the Atherosclerosis risk in communities (ARIC) study. Am Heart J 2002;144:233-8.

43. Schulze MB, Rimm EB, Li T, et al. C-Reactive protein and incident cardiovascular events among men with diabetes. Diabetes Care 2004;27:889-94.

44. Pasceri V, Willerson JT, Yeh ET. Direct proinflammatory effect of C-reactive protein on human endothelial cells. Circulation 2000;102:2165-8.

45. Pasceri V, Cheng JS, Willerson JT, et al. Modulation of C-reactive protein-mediated monocyte chemoattractant protein-1 induction in human endothelial cells by anti-atherosclerosis drugs. Circulation 2001;103:2531-4.

46. Torzewski M, Rist C, Mortensen RF, et al. C-Reactive protein in the arterial intima: role of C-reactive protein receptor-dependent monocyte recruitment in atherogenesis. Arterioscler Thromb Vasc Biol 2000;20:2094-9.
47. Zhang R, Becnel L, Li M, et al. C-Reactive protein impairs human CD14+ monocyte-derived dendritic cell differentiation, maturation and function. Eur J Immunol 2006;36:2993-3006.

48. Chang M-K, Binder CJ, Torzewski M, et al. C-Reactive protein binds to both oxidized LDL and apoptotic cells through recognition of a common ligand: phosphorylcholine of oxidized phospholipids. Proc Natl Acad Sci U S A 2002;99:13043-8.

49. Zwaka TP, Hombach V, Torzewski J. C-Reactive protein-mediated low density lipoprotein uptake by macrophages: implications for atherosclerosis. Circulation 2001;103:1194-7.

50. Williams TN, Zhang CX, Game BA, et al. C-reactive protein stimulates MMP-1 expression in U937 histiocytes through Fc[gamma]RII and extracellular signal-regulated kinase pathway:: an implication of CRP involvement in plaque destabilization. Arterioscler Thromb Vasc Biol 2004:24:61-6.

51. Nabata A, Kuroki M, Ueba $\mathrm{H}$, et al. C-Reactive protein induces endothelial cell apoptosis and matrix metalloproteinase-9 production in human mononuclear cells: implications for the destabilization of atherosclerotic plaque. Atherosclerosis 2008;196:129-35.

52. Lu J, Bi Y, Wang T, et al. The relationship between insulin-sensitive obesity and cardiovascular diseases in a Chinese population: results of the reaction study. Int J Cardiol 2014;172:388-94.

53. Tay YH, Nurjono M, Lee J. Increased Framingham 10-year CVD risk in Chinese patients with schizophrenia. Schizophr Res 2013;147:187-92.

54. Maluf CB, Barreto SM, dos Reis RCP, et al. Platelet volume is associated with the Framingham risk score for cardiovascular disease in the Brazilian longitudinal study of adult health (ELSABrasil). Clin Chem Lab Med 2016;54:879-87.

55. Ebrahimof S, Hosseini-Esfahani F, Mirmiran P, et al. Food patterns and Framingham risk score in Iranian adults: Tehran lipid and glucose study: 2005-2011. Metab Syndr Relat Disord 2018;16:64-71. 